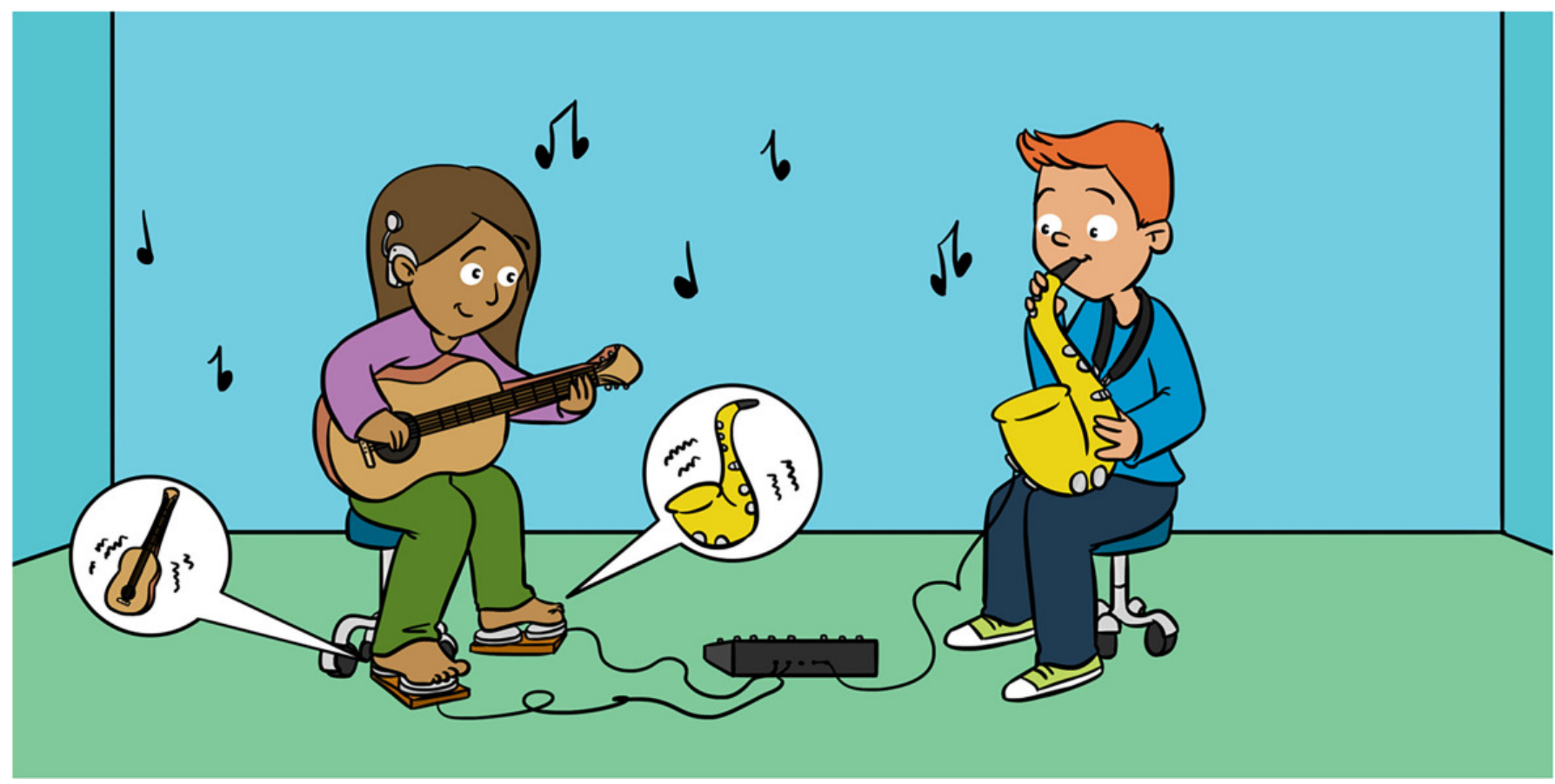

\title{
DEAFNESS AND MUSIC: CAN VIBRATION BE USED WHEN PLAYING MUSIC TOGETHER?
}

Carl Hopkins $^{1 *}$, Saúl Maté-Cid ${ }^{1}$, Robert Fulford ${ }^{2}$, Gary Seiffert ${ }^{1}$, Jane Ginsborg ${ }^{2}$ and Natalie Barker ${ }^{1}$ ${ }^{1}$ Acoustics Research Unit, University of Liverpool, Liverpool, United Kingdom

${ }^{2}$ Royal Northern College of Music, Manchester, United Kingdom

YOUNG REVIEWER:

ALEX

AGE: 11
Performing music or singing together provides people with great pleasure. But if you are deaf (or hard of hearing) it is not always possible to listen to other musicians while trying to sing or play an instrument. It can be particularly difficult to perceive different musical pitches with a hearing aid or other hearing-assistance device. However, the human body can transmit musical sounds to the brain when vibrations are applied to the skin. In other words, we can feel music. Our research has identified a safe way for deaf people to hear musical notes through the skin of their hands and feet. We have shown that vibration allows people to safely feel music on the skin. This approach allows people to identify a musical note as being higher or lower in pitch than other notes, and it helps musicians to play music together. 


\section{COCHLEAR}

IMPLANT

An electronic device inside the inner ear that helps a deaf person to hear.
MECHANORECEPTORS

Sensors in the body that respond to mechanical pressure or change of shape.

\section{INTRODUCTION}

The classical composer Beethoven composed some of his finest music when he was extremely deaf. How did he do this? It is said that he put a wooden stick between his teeth and pushed it against the piano to feel the vibrations. Dame Evelyn Glennie is a famous percussionist who happens to be deaf. When practicing and performing, she can feel the vibrations generated by her instruments.

Many adults who use hearing aids or cochlear implants have difficulty listening to music [1]. For adult musicians and singers who have hearing impairments, deafness can make it difficult to take part in music making [2]. There are 32 million deaf children in the world, so could vibration help them learn to play instruments and perform with other children? Our research investigated the range of musical notes that can be felt safely using vibration, and whether people can tell the difference between notes felt through vibrations.

\section{CAN WE HEAR THROUGH THE SKIN?}

Our ears convert sounds into signals that are sent to the brain so we can identify them. The outer part of the ear-the soft part on the outside of the head-is called the pinna. The pinna helps sound enter the ear canal, which is a short tube that leads to the eardrum in the middle ear. The sound makes the eardrum vibrate. These vibrations are sent to the cochlea in the inner ear by the vibration of very small bones. Inside the inner ear, there are tiny hair cells that are sensitive to vibration, and they convert the vibration into electrical signals to be sent to the brain. Hair cells are called mechanoreceptors because they are receptive to mechanical vibration.

When we feel vibration, signals are sent to the brain by different kinds of mechanoreceptors that are underneath the top layer of the skin. These mechanoreceptors are not as sensitive as those in our ears, but they allow us to feel vibration for some sounds that can be heard with our ears.

\section{CAN WE SAFELY APPLY VIBRATION TO HANDS AND FEET?}

Very loud sounds can damage the ears, so is vibration safe? When workers dig up roads using a pneumatic drill, they are exposed to high levels of vibration. This can cause a permanent health problem called hand-arm vibration syndrome that makes a person's fingers feel numb. To avoid this problem, we investigated whether a person could feel musical notes at low levels of vibration that were safe over a long period of time. This is important because musicians and singers spend many hours practicing their instruments. We used experiments to find 
Figure 1

Contact discs for (A) the fingertip, and (B) the heel and forefoot Both are connected to electrodynamic shakers that make the discs vibrate so that the user can feel the vibrations through the skin.

Figure 2

Musical notes on a piano keyboard. The notes within the red box can be used for the vibrotactile presentation of music. The higher notes, from A5 onward, are more difficult to feel. This indicates that the sense of hearing is more sensitive than the sense of touch.

\section{VIBROTACTILE} THRESHOLD

The lowest level at which a person can perceive vibration through touch.

\section{MUSICAL SCALE}

A group of notes arranged in order of their pitch.

\section{PITCH}

The lowness or highness of a note.

\section{OCTAVE}

The interval between two notes where one note has twice or half the frequency of vibration of the other.
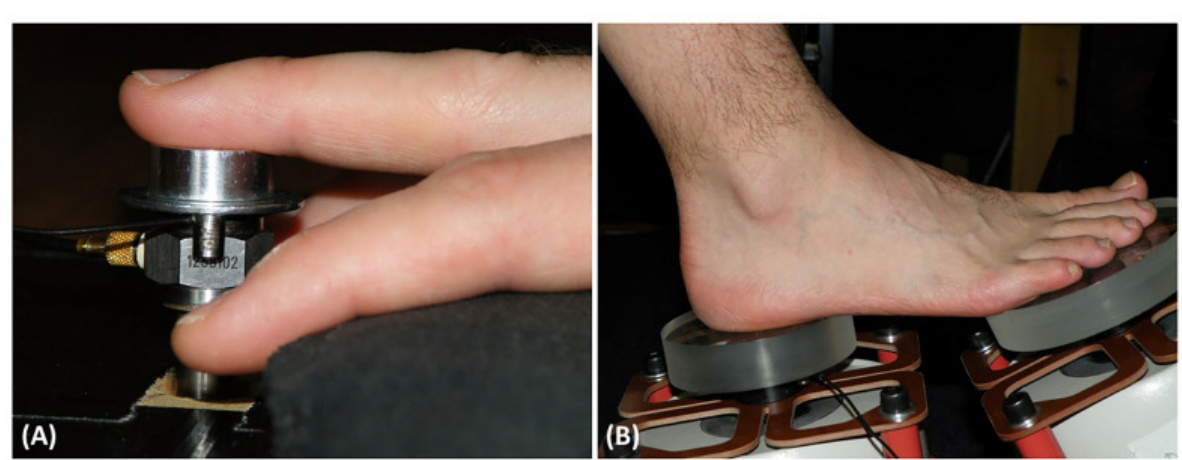

Figure 1

\section{||||||||||||||||||||||||||||||||||||||||

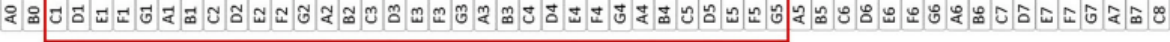

Figure 2

the lowest levels of vibration that people could feel on their fingertips and the soles of their feet [3]. This was done for different musical notes. These lowest levels are called vibrotactile thresholds. Vibro indicates vibration, tactile indicates the sense of touch, and threshold refers to the lowest level.

Why did we use the hairless skin on the palms of the hands and the soles of the feet? Because this skin is more sensitive than hairy skin, and therefore has a lower vibrotactile threshold. We thought that singers could use their fingertips to feel the vibrations caused by other musicians. However, musicians playing instruments with their hands would need to use their feet to feel the vibrations. To provide the vibration, we used a flat disc that contacts the hand or the foot, connected to a device called an electrodynamic shaker (Figure 1). Shakers are similar to loudspeakers, but instead of producing sound, they only make vibration. A loudspeaker is fragile and is easily damaged so it can not be touched, but a shaker is robust and can support the weight of a hand or foot.

In traditional Western music, a musical scale has seven notes. For example, the scale of $C$ major contains the following notes: $C, D, E$, F, G, A, B. Each note has a different pitch. You might remember the sound of these seven notes if you have ever sung the "Do-Re-Mi" tune because they are equal to "Do," "Re," "Mi," "Fa," "Sol," "La," "Ti." In Figure 2 you can see that these are the white notes on a piano keyboard. This sequence of notes is repeated across the entire keyboard, where the next $C$ is an octave higher in pitch. To name the notes in different octaves, a number is added after each note. For example, G5 refers to G in octave 5. 


\section{RELATIVE PITCH}

The ability to correctly recognize or produce a musical note in terms of its relative position in a musical scale.

\section{INTERVAL}

The distance in pitch between two notes.
Our experiments showed that all musical notes from C1 (low pitch) up to G5 (high pitch) can be felt clearly on hands and feet. Importantly, these notes could be felt at a safe level that avoided health problems. This range of notes covers more than four octaves, which includes most notes on a piano (Figure 2) and on many other instruments, as well as notes produced by the human voice. The fact that people have more difficulty feeling the high notes from A5 to C8 on the piano reminds us that the sense of touch is less sensitive than the sense of hearing.

For low-pitched notes, we found that the heel and the forefoot had lower vibrotactile thresholds than the fingertip. Most musicians can not use their fingertips while they are playing an instrument, so it is helpful that their feet are more sensitive, and they can use those to detect vibrations. We also found that the vibrotactile threshold for fingertips is similar for people with normal hearing and people who are deaf. This means that vibration could be used by everyone.

\section{CAN WE TELL THE DIFFERENCE BETWEEN MUSICAL NOTES USING VIBRATION?}

Identifying relative pitch is a useful skill for musicians. This means they can identify or sing a musical note after they have heard another note. Think about the "Do-Re-Mi" tune again. If you heard "Do" followed by "Mi" and had relative pitch skills, you would be able to say that "Mi" was a higher pitch than "Do." We carried out experiments with vibration to see if it was possible to identify one note as being higher or lower in pitch than another note when using the fingertip or forefoot [4]. The musicians with normal hearing carried out 16 short training sessions to see if they could improve their skill.

We found that wide pitch intervals were easier to identify than narrow intervals. A wide interval has notes that are far away from each other, such as from $C$ to $G$. In a narrow interval, the notes are close together, such as from $C$ to $\mathrm{D}$. In terms of "Do-Re-Mi," it was quite easy to tell "Do" from "Fa," "Sol," "La," and "Ti" but harder to tell "Do" from "Re" or "Mi." This happened with amateur and professional musicians with normal hearing as well as professional musicians with a hearing loss. The short training sessions improved the relative pitch skill of the musicians with normal hearing.

\section{HOW CAN VIBRATION BE USED TO PERFORM AND LEARN ABOUT MUSIC?}

Musicians can use vibration to help them learn an instrument and play music with other people, by sending the sound from each instrument to a mixing desk and then sending it back as vibration to the musician's 


\section{Figure 3}

Group musical performance using vibration. Green lines show sound picked up by microphones and taken to the mixing desk. Red lines indicate the "mixed" signal sent as vibration to the musician's feet.

\section{VIDEO 1}

Video showing the responses of staff and pupils at the Royal School for the Deaf Derby who used the vibrotactile equipment in their music lessons.

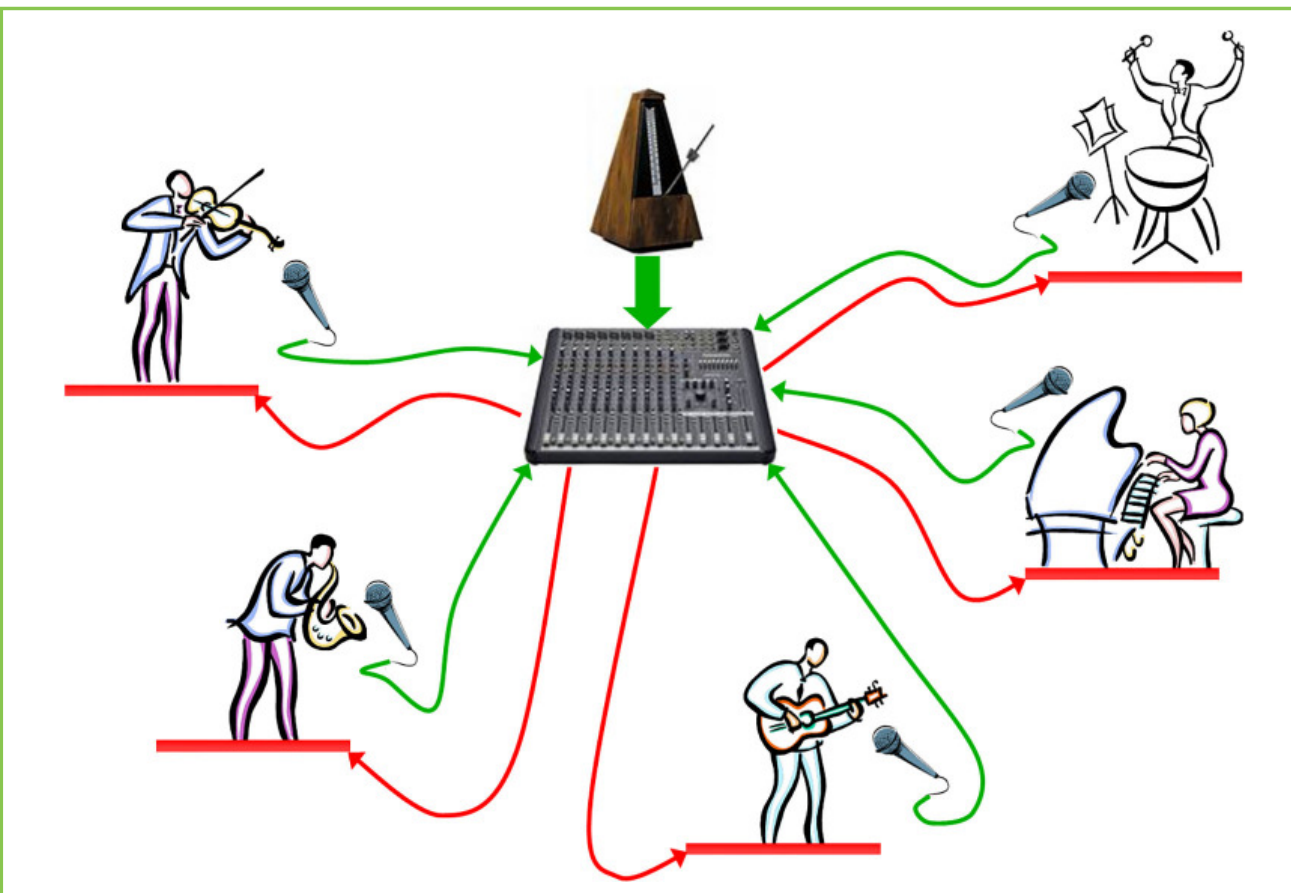

Figure 3

body (Figure 3). For example, a guitarist could choose to feel the drums on one foot and their own guitar on the other foot.

Our equipment was installed in the Royal School of the Deaf Derby. Video 1 shows the responses of staff and pupils who used the vibrotactile equipment to understand musical pitch and play music together in their lessons [5]. The music teacher, Matthew Taylor, found that the equipment made a positive change to his teaching and that it created a calmer atmosphere in the classroom. Matthew used the equipment to help his students make a connection between vibration and the pitch of a note. This helped the students decide if one note was higher or lower than another note. Matthew said that his students became more interested, independent, and active in music lessons, and that they really enjoyed playing music together.

\section{CONCLUSIONS}

Our research shows that vibration can be used at a safe level by people with hearing impairments to help them play music with other musicians. We hope this technique will provide more opportunities for children and adults with hearing impairments to perform, enjoy, and compose music. The research promotes inclusive music education by making music more accessible to children with hearing impairments. 


\section{ACKNOWLEDGMENTS}

This research was supported by the Arts and Humanities Research Council (AHRC) (Grant No. AH/H008926/1, 2010-2013). We would like to say a big thank you to staff and the pupils at Royal School for the Deaf Derby for letting us document their experiences.

\section{REFERENCES}

1. Greasley, A., Crook, H., and Fulford, R. 2020. Music listening and hearing aids: perspectives from audiologists and their patients. Int. J. Audiol. 59:694-706. doi: 10.1080/14992027.2020.1762126

2. Fulford, R., Ginsborg, J., and Goldbart, J. 2011. Learning not to listen: the experiences of musicians with hearing impairments. Music Educ. Res. 13:447-64. doi: 10.1080/14613808.2011.632086

3. Hopkins, C., Maté-Cid, S., Fulford, R., Seiffert, G., and Ginsborg, J. 2016. Vibrotactile presentation of musical notes to the glabrous skin for adults with normal hearing or a hearing impairment: thresholds, dynamic range and high-frequency perception. PLOS ONE. 11:e0155807. doi: 10.1371/journal.pone.0155807

4. Hopkins, C., Maté-Cid, S., Fulford, R., Seiffert, G., and Ginsborg, J. 2021. Perception and learning of relative pitch by musicians with using the vibrotactile mode. Mus. Sci. 1-24. doi: 10.1177/10298649211015278

5. Hopkins, C., Seiffert, G., and Barker, N. 2020. Vibrotactile Technology to Support d/Deaf People in Music Education: When Musical Vibrations Met Royal School for the Deaf Derby. Available online at: https://stream.liv.ac.uk/ 2qvwd9th (accessed June 29, 2021).

SUBMITTED: 29 June 2021; ACCEPTED: 20 December 2021; PUBLISHED ONLINE: 14 January 2022.

EDITOR: Naomi Curati, The University of Manchester, United Kingdom

SCIENCE MENTOR: Won Chan Oh

CITATION: Hopkins C, Maté-Cid S, Fulford R, Seiffert G, Ginsborg J and Barker N (2022) Deafness And Music: Can Vibration Be Used When Playing Music Together? Front. Young Minds 9:732713. doi: 10.3389/frym.2021.732713

CONFLICT OF INTEREST: The authors declare that the research was conducted in the absence of any commercial or financial relationships that could be construed as a potential conflict of interest.

COPYRIGHT @ 2022 Hopkins, Maté-Cid, Fulford, Seiffert, Ginsborg and Barker. This is an open-access article distributed under the terms of the Creative Commons Attribution License (CC BY). The use, distribution or reproduction in other forums is permitted, provided the original author(s) and the copyright owner(s) are credited and that the original publication in this journal is cited, in accordance with accepted academic practice. No use, distribution or reproduction is permitted which does not 

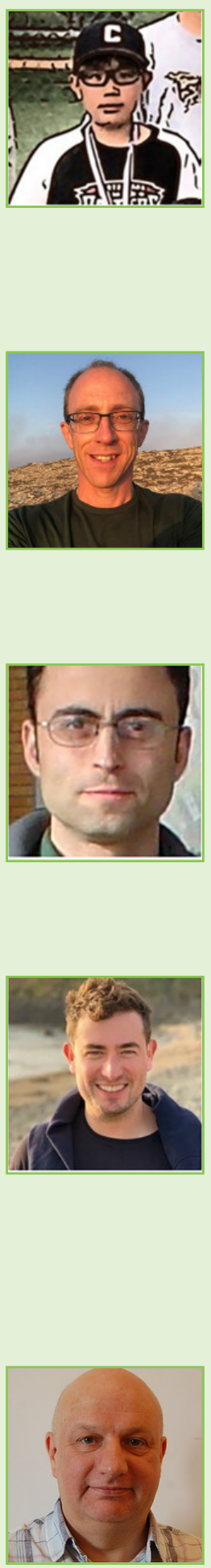

comply with these terms.

\section{YOUNG REVIEWER}

\section{ALEX, AGE: 11}

I like to play baseball and tennis. I like to go fishing anywhere, especially in FL. I also fly fish and like camping in the Rocky Mountains in CO. My favorite book series is the Spy School series and favorite colors are green and blue. Math and Science are my favorite subjects. I have one dog, one turtle, and twelve fish.

\section{AUTHORS}

\section{CARL HOPKINS}

I am a Professor in Acoustics and Head of the Acoustics Research Unit at the University of Liverpool. I was awarded the UK Institute of Acoustics Tyndall Medal in 2012 for achievements and services in the field of acoustics and the Engineering Medal in 2016. I am also a Fellow of the Institute of Acoustics. My research focuses on sound and vibration, and in my spare time I enjoy listening to, and playing music (more acoustics!). *carl.hopkins@liverpool.ac.uk

\section{SAÚL MATÉ-CID}

I am an acoustic engineer and a great fan of art and music. I gained a Bachelor's degree in Audio Technology from Salford University, a Diploma in Professional Studies at the Acoustics Group of Philips (Belgium), a Master's degree in Signal Processing from King's College London, and a PhD in Acoustics from the University of Liverpool. I am a member of the Audio Engineering Society with expertise in psychoacoustics, musical haptics, hearing protection, and electroacoustics.

\section{ROBERT FULFORD}

I am a Visiting Research Fellow in Music Psychology at the University of Leeds. My research interests include career development in teaching and the performing arts, work-life balance, recruitment and retention, diversity and inclusion, music perception and communication, and the use of hearing aid technology in music listening. My Ph.D., in Music Psychology explored how d/Deaf musicians access, rehearse and perform music with a focus on the use of vibrotactile feedback. I have Masters Degrees in Occupational and Educational Psychology and Level 2 British Sign Language. rjfulford@gmail.com

\section{GARY SEIFFERT}

I am a Senior Research Fellow in the Acoustics Research Unit at the University of Liverpool with over 40 years of experience in vibro-acoustic measurements. My Ph.D., was on the interaction of sound with powdered material and I continue research into acoustic cleaning of industrial spaces using very high levels of low frequency sound. I am a Hi-Fi enthusiast, amateur musician and all-round music lover so it was particularly satisfying to be involved in this research project to assist in music making for children with a hearing impairment. aru@liverpool.ac.uk 


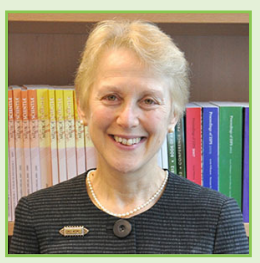

\section{JANE GINSBORG}

I was a professional singer before becoming a psychologist. I am Professor of Music Psychology and Associate Director of Research at the Royal Northern College of Music (Manchester, UK) where I have worked since 2005. I am a Former President of the European Society for the Cognitive Sciences of Music, and am currently Editor-in-Chief of Musicae Scientiae. I have written a textbook, Performing Music Research: Methods in Music Education, Psychology, and Performance Science, and many articles and book chapters on expert individual and collaborative practice, rehearsal and performance, particularly involving singing; musicians' health, well-being, literacy and resilience; practice-led research, and virtuosity. jane.ginsborg@rncm.ac.uk

\section{NATALIE BARKER}

I am a part-time Research Associate in music education for children with a hearing impairment. I am also a trained musician and music teacher and my work in the Acoustics Research Unit at the University of Liverpool looks at the introduction of vibrotactile technology into schools for the deaf. I teach at a secondary school in Liverpool and I am also a consultant for Sefton Music Hub, working on a resource toolkit to help classroom music teachers to embed careers into the key stage 3 curriculum. nbarker@mylhs.org 